\title{
Markers of systemic inflammation predict survival in patients with advanced renal cell cancer
}

\author{
P Fox ${ }^{1}$, M Hudson ${ }^{2}$, C Brown ${ }^{2}$, S Lord ${ }^{2}$, V Gebski ${ }^{2}$, P De Souza ${ }^{3,4}$ and C K Lee ${ }^{\star, 2,4}$ \\ ${ }^{1}$ Central West Cancer Service, Orange, NSW, Australia; ${ }^{2}$ National Health and Medical Research Council (NHMRC) Clinical Trials \\ Centre, The University of Sydney, Camperdown, NSW, Australia and ${ }^{3}$ University of Western Sydney, School of Medicine, Penrith, \\ NSW, Australia
}

Background: The host inflammatory response has a vital role in carcinogenesis and tumour progression. We examined the prognostic value of inflammatory markers (albumin, white-cell count and its components, and platelets) in pre-treated patients with advanced renal cell carcinoma (RCC).

Methods: Using data from a randomised trial, multivariable proportional hazards models were generated to examine the impact of inflammatory markers and established prognostic factors (performance status, calcium, and haemoglobin) on overall survival (OS). We evaluated a new prognostic classification incorporating additional information from inflammatory markers.

Results: Of the 416 patients, 362 were included in the analysis. Elevated neutrophil counts, elevated platelet counts, and a high neutrophil-lymphocyte ratio were significant independent predictors for shorter OS in a model with established prognostic factors. The addition of inflammatory markers improves the discriminatory value of the prognostic classification as compared with established factors alone (C-statistic 0.673 vs $0.654, P=0.002$ for the difference), with $25.8 \%(P=0.004)$ of patients more appropriately classified using the new classification.

Conclusion: Markers of systemic inflammation contribute significantly to prognostic classification in addition to established factors for pre-treated patients with advanced RCC. Upon validation of these data in independent studies, stratification of patients using these markers in future clinical trials is recommended.

In renal cell cancer (RCC), inactivation of the von Hippel-Lindau tumour-suppressor gene results in abnormal accumulation of hypoxia-inducible factor, resulting in dysregulation of cellular growth and angiogenesis (Kaelin, 2004; Lynch et al, 2004). Although the genetic basis of this disease and many other cancers are well established, recent work across different cancer populations also identified that host inflammatory response has an important role in carcinogenesis and disease progression (Colotta et al, 2009; Hanahan and Weinberg, 2011). Initial in-vitro study findings have been supported by results from clinical studies that demonstrated a correlation between clinical outcomes and laboratory markers of systemic inflammatory response, including plasma C-reactive protein (CRP) concentration (Canna et al, 2004; Hilmy et al, 2005), hypoalbuminaemia (Forrest et al, 2003), and the Glasgow Prognostic Score (GPS, which combines CRP and albumin) (Murri et al, 2006; Ramsey et al, 2007; Crumley et al, 2008).

There is also a growing body of evidence demonstrating that haematological markers of systemic inflammatory response such as absolute white-cell count or its components (neutrophils, neutrophil-lymphocyte ratios (NLR) (Yamanaka et al, 2007; Halazun et al, 2008, 2009; Liu et al, 2010; Chua et al, 2011;

\footnotetext{
*Correspondence: Dr CK Lee; E-mail: chee.lee@ctc.usyd.edu.au

${ }^{4}$ Both the authors contributed equally as senior authors to this study.
}

Received 14 March 2013; revised 22 May 2013; accepted 23 May 2013; published online 18 June 2013 
Huang et al, 2011), platelets, and platelet-lymphocyte ratios (PLR) (Heng et al, 2009; Smith et al, 2009) are also prognostic indicators for cancer clinical outcomes. These markers are inexpensive to test and routinely measured in day-to-day oncological practice, and hence potentially provide readily available objective information to help oncologists to estimate patient prognosis.

The value of prognostic models to improve categorisation of patient risk by incorporating information from multiple pretreatment factors is widely accepted in genitourinary oncology. In advanced RCC, one prognostic model in treatment-naive patients developed at the Memorial Sloan-Kettering Cancer Centre (MSKCC) (Motzer et al, 1999) has been widely adopted for enrichment and stratification of patients in clinical trials, and also used for patient counselling and risk-directed therapy. In patients who had prior cytokine therapy, a second prognostic model identified low Karnofsky Performance Status Scale (KPS), high corrected serum calcium, and low serum haemoglobin as predictors of shorter survival (Motzer et al, 2004b). In addition to the well-established MSKCC factors, some of the markers of systemic inflammatory response have also been identified as independent prognostic variables in treatment-naive patients (Heng et al, 2009; Huang et al, 2011). However, the value of these markers as independent prognostic factors and the extent these markers improve prognostic classification for patients with disease progression after front-line therapy remains unknown. In this study, we examined these questions in a population of patients treated with prior cytokine therapy; our hypothesis was that elevated inflammatory markers predicted for worse outcome.

\section{MATERIALS AND METHODS}

Patients. The patient population for this analysis comprised 416 patients with locally advanced or metastatic RCC who were treated with lapatinib or hormonal therapy after prior failure of immunotherapy in a randomised phase III trial (EGF20001) (Ravaud et al, 2008). The eligibility, methods, treatment plan, and outcome for this phase III trial have been previously published (Ravaud et al, 2008). Key eligibility criteria included a diagnosis of locally advanced or metastatic RCC not amenable to curative surgery or radiotherapy, measurable disease, progression after or intolerance to first-line cytokine-based therapy, adequate haematologic, renal, and hepatic function, KPS $\geqslant 70 \%$, and life expectan$c y \geqslant 12$ weeks. Lapatinib was administered orally at $1250 \mathrm{mg}$ daily; hormonal therapy was also administered daily, and consisted of megestrol acetate or tamoxifen as decided by the investigator. All patients provided written informed consent to participate in the randomised trial.

Baseline demographic, clinical, and laboratory data were collected prospectively on all patients as part of the clinical trial. Date of death or last follow-up was also recorded for all patients.

Statistical analysis. The end point of interest was overall survival (OS), defined as the time from randomisation to the date of death or date of last follow-up. We first evaluated the discriminative value of MSKCC-defined prognostic factors: Karnofsky Performance Status, haemoglobin level, and corrected serum calcium (Motzer et al, 2004b), in patients from the EGF20001 trial. These factors were examined individually in univariate analyses, and then in combination as multivariate models. Using the previously defined MSKCC classification (Motzer et al, 2004b), patients were grouped into good, intermediate, or poor risk groups based on the presence of none, one, or two to three baseline factors. Low Karnofsky Performance Status $(<80 \%)$, low haemoglobin level $\left(<13 \mathrm{~g} \mathrm{dl}^{-1}\right.$ for males and $<11.5 \mathrm{~g} \mathrm{dl}^{-1}$ for females), and high corrected serum calcium ( $\geqslant 10 \mathrm{mg} \mathrm{dl}^{-1}$ ) were considered to be risk factors for shorter OS.
We also individually examined the impact of each of the baseline markers of systemic inflammation (albumin, neutrophils, lymphocytes, platelets, NLR, and PLR) on OS. These markers were analysed as categorical variables. Dichotomisation of these variables was based on the upper (neutrophils and platelets) and the lower (albumin and lymphocytes) ranges of normal measurements for these markers.

For NLR and PLR, no widely accepted cutpoints have been adopted; therefore, we used the medians of distribution as cutpoints for dichotomisation. Previous studies examining NLR thresholds in advanced malignancy have used a cutpoint ranging from 2.5 to 5.0 (Yamanaka et al, 2007; Kao et al, 2010; Chua et al, 2011; Huang et al, 2011). A cutpoint ranging from 150 to 300 has been used for PLR (Aliustaoglu et al, 2010; Asher et al, 2011; He et al, 2013). We further examined the impact of other cutpoints as sensitivity analyses.

We then built a second multivariate model combining markers of systemic inflammation and MSKCC factors. A significant relationship between an inflammatory marker and OS (defined as $P<0.15)$ in univariate analyses was used as the criterion for including that marker in the multivariate backward stepwise elimination procedure. The final multivariate model retained all MSKCC factors; only markers of systemic inflammation with $P<0.05$ were retained. Patients were then reclassified using the new classification based on the presence of baseline factors identified to be significant in the final model.

We compared the discriminatory value of the two prognostic classifications (MSKCC classification and new classification with MSKCC factors and markers of systemic inflammation). The Kaplan-Meier curves were used to illustrate the differences in survival distribution for the different prognostic groups. We also compared the concordance statistics (C-statistic) (Harrell et al, 1996) to evaluate the differences in discrimination for the two classifications. The C-statistic is equivalent to the area under the receiver operating characteristic curve for censored data, in which a value of 0.5 indicates no discrimination, and a value of 1 represents a perfect ability to correctly rank randomly selected pairs of patients according to their survival times.

The incremental benefit of adding markers of systemic inflammation to the MSKCC factors to improve prognostic classification was evaluated by calculating the net reclassification index (NRI) (Pencina et al, 2008). First, patients were stratified into one risk category using the MSKCC classification (Motzer et al, 2004b). Then, we used the new classification (MSKCC factors with markers of systemic inflammation) to determine the risk category, to ascertain whether there would be improvement in the NRI that is, whether the proportion of patients who died would be assigned to a higher risk category and those who survived to a lower risk category.

\section{RESULTS}

Out of 416 patients enrolled in the EGF20001 randomised trial (Ravaud et al, 2008), a total of 362 patients (87\%) with complete baseline information on the MSKCC factors (Motzer et al, 2004b) and markers of systemic inflammation were available for analysis (Supplementary Figure 1). Patients $(n=54,17 \%)$ excluded from this analysis had a higher incidence of bone metastasis at baseline than those included in the analysis. The other baseline characteristics were similar for patients included in this analysis, and for those excluded due to missing information (Table 1).

Impact of MSKCC factors on OS. In univariate analyses, low KPS, high corrected serum calcium, and low serum haemoglobin were predictors of shorter OS (Table 2). These three predictors 
remained significant when they were examined together in a multivariate model.

The good-prognosis group (no risk factors) comprised 153 patients (42\%) with a median OS of 18.5 months (95\% CI

Table 1. Baseline characteristics of patients included in and excluded from this study

\begin{tabular}{|c|c|c|c|c|c|}
\hline & \multicolumn{2}{|c|}{$\begin{array}{c}\text { Patients } \\
\text { included } \\
\text { in this study } \\
(n=362)\end{array}$} & \multicolumn{2}{|c|}{$\begin{array}{l}\text { Patients } \\
\text { excluded from } \\
\text { this study } \\
(n=54)\end{array}$} & \\
\hline Characteristics & $n$ & $\%$ & $n$ & $\%$ & $\boldsymbol{P}$-value \\
\hline \multicolumn{6}{|l|}{ Age, years } \\
\hline $\begin{array}{l}\text { Median } \\
\text { Range }\end{array}$ & & $\begin{array}{c}62 \\
19-84\end{array}$ & & $\begin{array}{c}60 \\
34-81\end{array}$ & 0.11 \\
\hline Gender & & & & & 0.39 \\
\hline $\begin{array}{l}\text { Female } \\
\text { Male }\end{array}$ & $\begin{array}{r}94 \\
268\end{array}$ & $\begin{array}{l}26 \\
74\end{array}$ & $\begin{array}{l}17 \\
37\end{array}$ & $\begin{array}{l}31 \\
69\end{array}$ & \\
\hline KPS & & & & & 0.95 \\
\hline $\begin{array}{l}70-80 \% \\
90-100 \%\end{array}$ & $\begin{array}{l}149 \\
213\end{array}$ & $\begin{array}{l}41 \\
59\end{array}$ & $\begin{array}{l}22 \\
32\end{array}$ & $\begin{array}{l}41 \\
59\end{array}$ & \\
\hline Previous nephrectomy & & & & & 0.20 \\
\hline $\begin{array}{l}\text { Yes } \\
\text { No }\end{array}$ & $\begin{array}{r}339 \\
23\end{array}$ & $\begin{array}{r}94 \\
6\end{array}$ & $\begin{array}{r}48 \\
6\end{array}$ & $\begin{array}{l}89 \\
11\end{array}$ & \\
\hline Histology & & & & & 0.84 \\
\hline $\begin{array}{l}\text { Clear cell } \\
\text { Non-clear cell }\end{array}$ & $\begin{array}{r}315 \\
43\end{array}$ & $\begin{array}{l}88 \\
12\end{array}$ & $\begin{array}{r}47 \\
7\end{array}$ & $\begin{array}{l}87 \\
13\end{array}$ & \\
\hline No. of metastatic sites & & & & & 0.64 \\
\hline $\begin{array}{l}\leqslant 2 \\
>2\end{array}$ & $\begin{array}{l}182 \\
180\end{array}$ & $\begin{array}{l}50 \\
50\end{array}$ & $\begin{array}{l}29 \\
25\end{array}$ & $\begin{array}{l}54 \\
46\end{array}$ & \\
\hline
\end{tabular}

Sites of metastasis

\begin{tabular}{|l|r|r|r|l|l|}
\hline Lung & 295 & 81 & 41 & 76 & 0.33 \\
Bone & 104 & 29 & 24 & 44 & 0.02 \\
Liver & 81 & 22 & 15 & 28 & 0.38 \\
Lymph nodes & 174 & 48 & 25 & 46 & 0.79 \\
\hline Randomised treatment & & & & & 0.80 \\
\hline Hormone therapy & 181 & 50 & 26 & 48 & \\
Lapatinib & 181 & 50 & 28 & 52 & \\
\hline
\end{tabular}

Abbreviation: KPS = Karnofsky Performance Status Scale.
16.5-20.2). The intermediate-prognosis group (one risk factor) comprised 111 patients (31\%) with a median OS of 10.6 months (95\% CI 8.2-12.7). The poor-prognosis group (two or more risk factors) comprised 98 patients (27\%) with a median OS of 5.8 months (95\% CI 4.3-7.2) (Figure 1a).

Impact of markers of systemic inflammation on OS. In univariate analyses, low serum albumin, elevated neutrophil counts, elevated platelet counts, and low lymphocyte counts were predictors of shorter OS (Table 3). High NLR and PLR were also predictors of shorter survival.

In a multivariate model of markers of systemic inflammation combined with MSKCC factors, elevated neutrophil counts, elevated platelet counts, and a high NLR were significant independent predictors of shorter OS (Table 3). Low KPS and high corrected serum calcium remained significant factors but not low serum haemoglobin $(P=0.09)$ in this model.

When other cutpoints for NLR and PRL were examined, similar outcomes were obtained (results not shown).

In this new prognostic model, the good-prognosis group (no risk factors) comprised 95 patients $(26 \%)$ with a median OS of 18.8 months (95\% CI 17.1-21.8). A new risk factor group, goodintermediate-prognosis group (one risk factor), comprised 85 patients $(24 \%)$ with a median OS of 16.5 months $(95 \%$ CI 12.3-19.3). The intermediate-prognosis group (two risk factors) comprised 74 patients (20\%) with a median OS of 11.2 months (95\% CI 7.8-13.2). The poor-prognosis group (three or more risk factor) comprised 108 patients (30\%) with a median OS of 6.0 months (95\% CI 4.3-7.2) (Figure 1b).

Performance of new prognostic classification. The C-statistic of the MSKCC classification was 0.654 (95\% CI 0.623-0.685). With the new classification, the C-statistic improved to 0.673 (95\% CI $0.643-0.703)$. The improvement of the C-statistic by 0.019 is statistically significant $(P=0.002)$.

Net reclassification. Table 4 illustrates the reclassification of patients' prognostic category using the new classification. Among the patients who were alive at 12 months, $22 \%$ of patients were classified to a higher risk category and $29 \%$ of patients were classified to a lower risk category, with an NRI of $6.8 \%$ (11 of 161 patients). Among the patients who had died at 12 months, $16 \%$ of patients were classified to a higher risk category and $35 \%$ of patients were classified to a lower risk category, with an NRI of $19.0 \%$ (34 of 179 patients). The total overall net reclassification was $25.8 \%(P=0.004)$.

Table 2. Univariate and multivariate analyses of MSKCC factors ${ }^{\mathrm{a}}$ on overall survival

Univariate analysis

Multivariate analysis

\begin{tabular}{|c|c|c|c|c|c|c|c|c|c|}
\hline Factors & $n$ & HR & $95 \%$ & $\mathrm{Cl}$ & $\boldsymbol{P}$-value & HR & $95 \%$ & $\mathrm{Cl}$ & $\boldsymbol{P}$-value \\
\hline$K P S<80$ & 59 & 2.86 & 2.13 & 3.85 & $<.0001$ & 2.33 & 1.71 & 3.18 & $<.0001$ \\
\hline$K P S \geqslant 80$ & 303 & 1.00 & & & & 1.00 & & & \\
\hline Low haemoglobin ${ }^{\mathbf{b}}$ & 169 & 1.93 & 1.53 & 2.44 & $<.0001$ & 1.41 & 1.09 & 1.83 & 0.009 \\
\hline Normal haemoglobin ${ }^{\mathbf{b}}$ & 193 & 1.00 & & & & 1.00 & & & \\
\hline Corrected calcium $\geqslant 10 \mathrm{mg} \mathrm{dl}^{-1}$ & 98 & 2.26 & 1.74 & 2.94 & $<.0001$ & 1.89 & 1.44 & 2.49 & $<.0001$ \\
\hline Corrected calcium $<10 \mathrm{mg} \mathrm{dl}^{-1}$ & 264 & 1.00 & & & & 1.00 & & & \\
\hline
\end{tabular}

Abbreviations: $\mathrm{Cl}=$ confidence interval; $\mathrm{HR}=$ hazard ratio; $\mathrm{MSKCC}=$ Memorial Sloan-Kettering Cancer Centre; KPS = Karnofsky Performance Status Scale

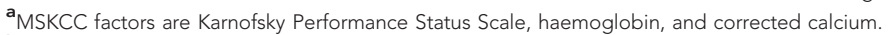

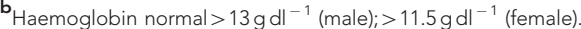



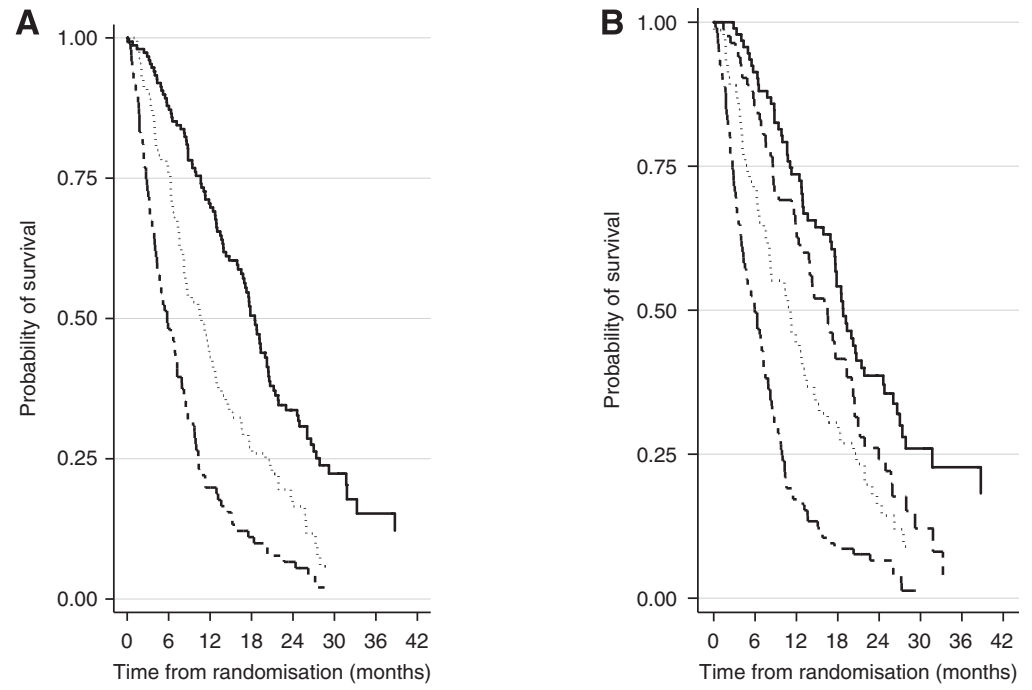

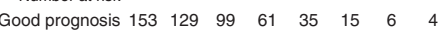

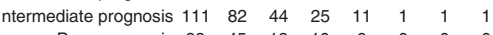

$\begin{array}{llllllllll}\text { Poor prognosis } & 98 & 45 & 18 & 10 & 6 & 0 & 0 & 0\end{array}$

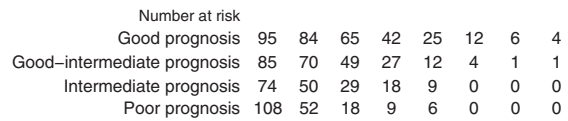

Figure 1. (A) Kaplan-Meier estimates of the probability of survival according to prognostic groups as defined by MSKCC* factors. (B) Kaplan-Meier estimates of the probability of survival according to prognostic groups as defined by markers of systemic inflammation ${ }^{\dagger}$ and MSKCC*. MSKCC = Memorial Sloan-Kettering Cancer Centre. *MSKCC factors are Karnofsky Performance Status Scale, haemoglobin, and corrected calcium. 'Systemic inflammation markers are neutrophils, platelets, and neutrophils-lymphocytes ratio. (A) Good prognosis is represented by the solid line, intermediate prognosis by the dotted line, and poor prognosis by the solid-dashed line. (B) Good prognosis is represented by the solid line, good-intermediate prognosis by the dashed line, intermediate prognosis by the dotted line, and poor prognosis by the solid-dashed line.

\section{DISCUSSION}

In this study, we confirmed that the MSKCC-defined factors of low Karnofsky Performance Status, low haemoglobin level, and high corrected serum calcium are independent and significant predictors of shorter OS in patients with advanced RCC treated with prior cytokine therapy. We also found that markers of systemic inflammation (elevated neutrophil counts, elevated platelet counts, and a high NLR) significantly predict for shorter OS. We demonstrated that the addition of inflammatory markers improves the discriminatory performance of the prognostic classification based on MSKCC factors alone (C-statistics 0.673 vs 0.654 , $P=0.002$ for the difference), with $25.8 \%$ of patients more appropriately classified using the new classification (Table 4). This new prognostic classification also better discriminates the 'good' and 'intermediate' prognosis patients by extending the risk classification to include a new 'good-intermediate' risk group.

The development of prognostic models to allow more accurate classification of patient survival time has many important implications. In the treatment-naive setting, the first MSKCC model (Motzer et al, 1999) has already been widely used for enrichment of patients in clinical trials according to risk (Escudier et al, 2007; Hudes et al, 2007; Motzer et al, 2007). In clinical practice, risk-directed treatment strategies are widely employed in the management of patients with newly diagnosed advanced RCC (Motzer et al, 2004a). However, there remains no standard agent or combination therapies recognised as effective salvage therapy following failure of front-line therapy. With many of these patients who were initially treated with effective front-line therapies but developed disease progression subsequently, accurate prognostic models are now urgently needed to better stratify these patients as they are being enrolled into second-line clinical trials of novel therapy.

Albumin, neutrophils, platelets, and lymphocytes are among the most frequently requested clinical laboratory tests together with haemoglobin and calcium in the oncology outpatient setting. The modern day automated blood cell analyser is precise and accurate in quantification of haemoglobin, platelets, and various white blood cell populations present in peripheral venous blood (Buttarello and Plebani, 2008). Furthermore, there is a standardisation of laboratory measurements of albumin, with internationally agreed standards, on definition and application of a reference measurement system for calibration and validation of routine methods (Infusino et al, 2011). These widely available and inexpensive routinely performed tests, which are accurate and standardised in many settings, provide oncologists with convenient and objective information to estimate patient prognosis.

This study also provides insight into the role of the host inflammatory response in cancer progression. Our findings can be used to raise hypotheses about the complex interactions of host factors (poor performance status), tumour biology (low haemoglobin and high calcium), and systemic inflammation (elevated neutrophil count, elevated platelet count, and a high NLR) and their effects on poorer survival in patients with metastatic RCC. An inflammatory microenvironment has recently been described as one of the hallmarks of cancer (Hanahan and Weinberg, 2011). Almost 150 years since Virchow originally postulated the relationship between inflammation and carcinogenesis (Balkwill and Mantovani, 2001), contemporary studies have confirmed that mitogenesis originates in an inflammatory microenvironment, and chronic inflammation persists throughout the disease course (Lu et al, 2006). This inflammatory milieu allows tumour cells to evade host responses, contributing to angiogenesis, tumour growth, invasion, and metastasis.

Promotion of the extrinsic pathway (pre-existing inflammation) or the intrinsic pathway (oncogene activation) results in mobilisation of transcription factors and inflammatory mediators, giving rise to recruitment of inflammatory cells including neutrophils, and megakaryocytes causing thrombocytosis (Mantovani et al, 2008). The resulting cascade of inflammatory mediators leads to 
Table 3. Univariate and multivariate analyses of MSKCC $^{\mathbf{a}}$ and systemic inflammation markers ${ }^{\mathbf{b}}$ on overall survival

Univariate analysis

Multivariate model

\begin{tabular}{|c|c|c|c|c|c|c|c|c|c|}
\hline Factors & n & HR & $95 \%$ & $\mathrm{Cl}$ & $\boldsymbol{P}$-value & HR & $95 \%$ & $\mathrm{Cl}$ & $\boldsymbol{P}$-value \\
\hline Neutrophils $\geqslant 7.5 \times 10^{9} / /$ & 41 & 2.71 & 1.91 & 3.84 & $<.0001$ & 1.66 & 1.12 & 2.45 & 0.01 \\
\hline Neutrophils $<7.5 \times 10^{9} / 1$ & 321 & 1.00 & & & & 1.00 & & & \\
\hline Platelets $\geqslant 400 \times 10^{9} / 1$ & 80 & 2.24 & 1.72 & 2.92 & $<.0001$ & 1.48 & 1.09 & 2.00 & 0.01 \\
\hline Platelets $<400 \times 10^{9} / \mathrm{I}$ & 282 & 1.00 & & & & 1.00 & & & \\
\hline Albumin $\leqslant 35 \mathrm{mg} \mathrm{dl}^{-1}$ & 69 & 2.48 & 1.87 & 3.30 & $<.0001$ & & & & \\
\hline Albumin $>35 \mathrm{mg} \mathrm{dl}^{-1}$ & 293 & 1.00 & & & & & & & \\
\hline Lymphocytes $<1.0 \times 10^{9} / \mathrm{I}$ & 66 & 1.54 & 1.15 & 2.07 & 0.004 & & & & \\
\hline Lymphocytes $\geqslant 1.0 \times 10^{9} / 1$ & 296 & 1.00 & & & & & & & \\
\hline Neutrophils/lymphocytes ratio $>3$ & 188 & 1.87 & 1.48 & 2.37 & $<.0001$ & 1.42 & 1.10 & 1.84 & 0.008 \\
\hline Neutrophils/lymphocytes ratio $\leqslant 3$ & 174 & 1.00 & & & & 1.00 & & & \\
\hline Platelets/lymphocytes ratio $>195$ & 178 & 1.88 & 1.48 & 2.37 & $<.0001$ & & & & \\
\hline Platelets/lymphocytes ratio $\leqslant 195$ & 184 & 1.00 & & & & & & & \\
\hline $\mathrm{KPS}<80$ & 59 & 2.86 & 2.13 & 3.85 & $<.0001$ & 2.27 & 1.66 & 3.09 & $<.0001$ \\
\hline$K P S \geqslant 80$ & 303 & 1.00 & & & & 1.00 & & & \\
\hline Corrected calcium $\geqslant 10 \mathrm{mg} \mathrm{dl}^{-1}$ & 98 & 2.26 & 1.74 & 2.94 & $<.0001$ & 1.53 & 1.15 & 2.04 & 0.003 \\
\hline Corrected calcium $<10 \mathrm{mg} \mathrm{dl}^{-1}$ & 264 & 1.00 & & & & 1.00 & & & \\
\hline Low haemoglobin ${ }^{d}$ & 169 & 1.93 & 1.53 & 2.44 & $<.0001$ & 1.27 & 0.97 & 1.67 & 0.09 \\
\hline Normal haemoglobin ${ }^{d}$ & 193 & 1.00 & & & & 1.00 & & & \\
\hline
\end{tabular}

Abbreviations: $\mathrm{Cl}=$ confidence interval; $\mathrm{HR}=$ hazard ratio; $\mathrm{KPS}=$ Karnofsky Performance Status Scale; MSKCC=Memorial Sloan-Kettering Cancer Centre

${ }^{\text {a } M S K C C}$ factors are Karnofsky Performance Status Scale, haemoglobin, and corrected calcium.

bystemic inflammation markers are neutrophils, platelets, and neutrophils-lymphocytes ratio.

${ }^{c}$ Multivariate model retained all MSKCC factors, and only systemic inflammation factors with $P<0.05$

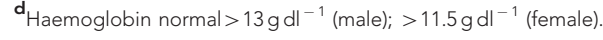

Table 4. Reclassification of patients' prognostic classification after addition of markers of systemic inflammation ${ }^{a}$ to MSKCC $^{b}$ factors

\section{Reclassification}

Good-

Good intermediate Intermediate Poor

Original prognostic

classification

Number of patients

\section{Patients who died at 12 months}

\begin{tabular}{|l|r|r|r|c|}
\hline Good & 24 & 16 & 2 & 1 \\
\hline Intermediate & 9 & 21 & 21 & 10 \\
\hline Poor & 0 & 5 & 28 & 42 \\
\hline
\end{tabular}

Patients alive at 12 months

\begin{tabular}{|l|r|r|r|r|}
\hline Good & 65 & 30 & 3 & 1 \\
Intermediate & 16 & 17 & 9 & 2 \\
Poor & 0 & 6 & 8 & 4 \\
\hline
\end{tabular}

Abbreviation: MSKCC = Memorial Sloan-Kettering Cancer Centre.

${ }^{a_{S}}$ ystemic inflammation markers are neutrophils, platelets, and neutrophils-lymphocytes ratio.

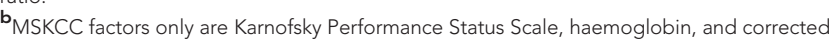
calcium.

c'Twenty-two patients excluded because the follow-up time is $<12$ months and the survival status censored.

tumour promotion, invasion, and metastasis. The complex array of leukocytes and inflammatory mediators in the tumour microenvironment may be reflected in the peripheral circulation.
Neutrophilia and elevated NLR convey a poor prognosis in a variety of clinical settings including critical illness, coronary interventions, and advanced malignancies (Zahorec, 2001; Poludasu et al, 2009; Proctor et al, 2012). Furthermore, these markers of inflammation are associated with increased risk of recurrence following surgical resection in localised cancers including RCC (Ohno et al, 2010). In colorectal cancer, normalisation of elevated NLR after one cycle of chemotherapy is associated with improved outcomes (Chua et al, 2011). These findings suggest that a systemic inflammatory state may be established long before metastases become clinically evident, and abrogation of systemic inflammation may occur in response to effective therapies. The NLR is a composite of both neutrophilia and lymphopenia, which together reflect the systemic inflammatory response in these white-cell lineages in malignancy (Leitch et al, 2007).

We demonstrated that an elevated platelet count is an independent predictor of poor prognosis in the second-line setting. A previous study also established thrombocytosis as an independent adverse prognostic factor in patients with RCC treated with VEGF targeted therapy (Heng et al, 2009). The activation and aggregation of platelets occurs in response to inflammatory cytokines and ADP released from tumour cells (Alexandrakis et al, 2003; Suzuki et al, 2004). The interaction between platelets and tumour cells facilitates invasion and metastasis (Suzuki et al, 2004). The association between tumour-related thrombocytosis and elevated inflammatory markers (IL-1, IL-6, TNF $\alpha$, CRP, and ferritin) suggests that platelet activation may reflect a systemic inflammatory state (Alexandrakis et al, 2003).

This study has a number of strengths. We were able to validate the prognostic values of MSKCC factors and evaluate the role of new markers of systemic inflammation using high quality 
randomised trial data. As the C-statistic is often criticised for its limited clinical interpretability (Vickers, 2011), we have further provided oncologists with the practical approach of using NRI to gauge the extent to which the new prognostic classification correctly reclassifies patients' levels of risk. As there was no significant difference in the treatment effect of the randomised agents in the EGF20001 trial, the baseline prognosis of patients would not have been modified by the treatment assignment.

This study has several limitations. The models were developed in patients previously treated with immunotherapy. Patients with metastatic RCC today have access to a larger number of effective therapies, such as sunitinib, sorafenib, and bevacizumab; these agents have revolutionised the treatment of metastatic RCC and have largely replaced immunotherapy as the first-line standard of care in routine clinical practice. For simplicity, we have assumed all factors identified in the multivariate models to have equal importance. This provides a straightforward extension of the widely accepted MSKCC approach. However, equal weighting of the importance of each factor could reduce precision and potentially misclassify some patients' prognosis. As the primary objective of the EGF20001 trial was not to investigate the impact of markers of systemic inflammation on OS, the trial protocol did not specify quantitative methods and reproducibility in the measurement of these markers, and this information was not collected to allow a complete assessment and reporting of assay methods to address the REMARK criteria (McShane et al, 2005). We have also not validated these markers as new prognostic factors in an independent cohort of similar patients. As patients in this data set were selected for the EGF20001 trial, the applicability of this new prognostic model in the wider non-trial population remains unknown.

In conclusion, an elevated neutrophil count, an elevated platelet count, and a high NLR contribute significantly to prognostic classification in addition to MSKCC factors for previously treated patients with advanced RCC. These markers reflect the importance of systemic inflammation in determining survival for these patients. Upon validation of these results in independent studies, stratification of patients using these markers in future clinical trials can be recommended.

\section{ACKNOWLEDGEMENTS}

We acknowledge the editorial support provided by Dr Sophie Gibbs.

\section{REFERENCES}

Alexandrakis MG, Passam FH, Moschandrea IA, Christophoridou AV, Pappa CA, Coulocheri SA, Kyriakou DS (2003) Levels of serum cytokines and acute phase proteins in patients with essential and cancer-related thrombocytosis. Am J Clin Oncol 26(2): 135-140.

Aliustaoglu M, Bilici A, Ustaalioglu B, Konya V, Gucun M, Seker M, Gumus M (2010) The effect of peripheral blood values on prognosis of patients with locally advanced gastric cancer before treatment. Med Oncol 27(4): 1060-1065.

Asher V, Lee J, Innamaa A, Bali A (2011) Preoperative platelet lymphocyte ratio as an independent prognostic marker in ovarian cancer. Clin Transl Oncol 13(7): 499-503.

Balkwill F, Mantovani A (2001) Inflammation and cancer: back to Virchow? Lancet 357(9255): 539-545.

Buttarello M, Plebani M (2008) Automated blood cell counts. Am J Clin Pathol 130(1): 104-116.

Canna K, McMillan DC, McKee RF, McNicol AM, Horgan PG, McArdle CS (2004) Evaluation of a cumulative prognostic score based on the systemic inflammatory response in patients undergoing potentially curative surgery for colorectal cancer. Br J Cancer 90(9): 1707-1709.
Chua W, Charles KA, Baracos VE, Clarke SJ (2011) Neutrophil/lymphocyte ratio predicts chemotherapy outcomes in patients with advanced colorectal cancer. Br J Cancer 104(8): 1288-1295.

Colotta F, Allavena P, Sica A, Garlanda C, Mantovani A (2009) Cancer-related inflammation, the seventh hallmark of cancer: links to genetic instability. Carcinogenesis 30(7): 1073-1081.

Crumley AB, Stuart RC, McKernan M, McDonald AC, McMillan DC (2008) Comparison of an inflammation-based prognostic score (GPS) with performance status (ECOG-ps) in patients receiving palliative chemotherapy for gastroesophageal cancer. J Gastroenterol Hepatol 23: e325-e329.

Escudier B, Eisen T, Stadler WM, Szczylik C, Oudard S, Siebels M, Negrier S, Chevreau C, Solska E, Desai AA, Rolland F, Demkow T, Hutson TE, Gore M, Freeman S, Schwartz B, Shan M, Simantov R, Bukowski RM (2007) Sorafenib in advanced clear-cell renal-cell carcinoma. N Engl J Med 356(2): 125-134.

Forrest LM, McMillan DC, McArdle CS, Angerson WJ, Dunlop DJ (2003) Evaluation of cumulative prognostic scores based on the systemic inflammatory response in patients with inoperable non-small-cell lung cancer. Br J Cancer 89: 1028-1030.

Halazun K, Hardy MA, Rana AA, Woodland DC, Luyten EJ, Mahadev S, Witkowski P, Stegel AB, Brown RS, Emond JC (2009) Negative impact of neutrophil lymphocyte ratio on outcome after liver transplantation for hepatocellular carcinoma. Ann Surg 250: 141-151.

Halazun KJ, Aldoori A, Malik HZ, Al-Mukhtar A, Prasad KR, Toogood GJ, Lodge JP (2008) Elevated preoperative neutrophil to lymphocyte ratio predicts survival following hepatic resection for colorectal liver metastases. Eur J Surg Oncol 34: 55-60.

Hanahan D, Weinberg RA (2011) Hallmarks of cancer: the next generation. Cell 144(5): 646-674.

Harrell FE, Lee KL, Mark DB (1996) Multivariable prognostic models: issues in developing models, evaluating assumptions and adequacy, and measuring and reducing errors. Stat Med 15(4): 361-387.

He W, Yin C, Guo G, Jiang C, Wang F, Qiu H, Chen X, Rong R, Zhang B, Xia L (2013) Initial neutrophil lymphocyte ratio is superior to platelet lymphocyte ratio as an adverse prognostic and predictive factor in metastatic colorectal cancer. Med Oncol 30(1): 1-6.

Heng DY, Xie W, Regan MM, Warren MA, Golshayan AR, Sahi C, Eigl BJ, Ruether JD, Cheng T, North S, Venner P, Knox JJ, Chi KN, Kollmannsberger C, McDermott DF, Oh WK, Atkins MB, Bukowski RM, Rini BI, Choueiri TK (2009) Prognostic factors for overall survival in patients with metastatic renal cell carcinoma treated with vascular endothelial growth factor-targeted agents: results from a large, multicenter study. J Clin Oncol 27(34): 5794-5799.

Hilmy M, Bartlett JMS, Underwood MA, McMillan DC (2005) The relationship between the systemic inflammatory response and survival in patients with transitional cell carcinoma of the urinary bladder. Br J Cancer 92: 625-627.

Huang P, Carducci MA, Eisenberger MA, Pili R, Kim JJ, Antonarakis ES, Hammers HJ, Keizman D (2011) The association of pretreatment (pre-tx) neutrophil to lymphocyte ratio (NLR) with outcome of sunitinib tx in patients (pts) with metastatic renal cell carcinoma (mRCC). J Clin Oncol 29(15_suppl): 4621.

Hudes G, Carducci M, Tomczak P, Dutcher J, Figlin R, Kapoor A, Staroslawska E, Sosman J, McDermott D, Bodrogi I, Kovacevic Z, Lesovoy V, Schmidt-Wolf IGH, Barbarash O, Gokmen E, O'Toole T, Lustgarten S, Moore L, Motzer RJ (2007) Temsirolimus, Interferon Alfa, or both for advanced renal-cell carcinoma. N Engl J Med 356(22): 2271-2281.

Infusino I, Braga F, Mozzi R, Valente C, Panteghini M (2011) Is the accuracy of serum albumin measurements suitable for clinical application of the test? Clin Chim Acta 412(9-10): 791-792.

Kaelin WG (2004) The Von Hippel-Lindau tumor suppressor gene and kidney cancer. Clin Cancer Res 10(18): 6290S-6295S.

Kao SCH, Pavlakis N, Harvie R, Vardy JL, Boyer MJ, van Zandwijk N, Clarke SJ (2010) High blood neutrophil-to-lymphocyte ratio is an indicator of poor prognosis in malignant mesothelioma patients undergoing systemic therapy. Clin Cancer Res 16(23): 5805-5813.

Leitch EF, Chakrabarti M, Crozier JE, McKee RF, Anderson JH, Horgan PG, McMillan DC (2007) Comparison of the prognostic value of selected markers of the systemic inflammatory response in patients with colorectal cancer. Br J Cancer 97(9): 1266-1270.

Liu H, Liu G, Bao Q, Sun W, Bao H, Bi L, Wen W, Liu Y, Wang Z, Yin X, Bai Y, Hu X (2010) The Baseline Ratio of neutrophils to lymphocytes is 
associated with patient prognosis in rectal carcinoma. J Gastrointest Cancer 41: 116-120.

Lu H, Ouyang W, Huang C (2006) Inflammation, a key event in cancer development. Mol Cancer Res 4(4): 221-233.

Lynch TJ, Bell DW, Sordella R, Gurubhagavatula S, Okimoto RA, Brannigan BW, Harris PL, Haserlat SM, Supko JG, Haluska FG, Louis DN, Christiani DC, Settleman J, Haber DA (2004) Activating mutations in the epidermal growth factor receptor underlying responsiveness of non-small-cell lung cancer to gefitinib. N Engl J Med 350(21): 2129-2139.

Mantovani A, Allavena P, Sica A, Balkwill F (2008) Cancer-related inflammation. Nature 454(7203): 436-444.

McShane LM, Altman DG, Sauerbrei W, Taube SE, Gion M, Clark GM. Diagnostics ftSSotN-EWGoC (2005) Reporting recommendations for tumor marker prognostic studies (REMARK). J Natl Cancer Inst 97(16): $1180-1184$.

Motzer RJ, Bacik J, Mazumdar M (2004a) Prognostic factors for survival of patients with stage IV renal cell carcinoma: Memorial Sloan-Kettering Cancer Center Experience. Clin Cancer Res 10(18): 6302S-6303S.

Motzer RJ, Bacik J, Schwartz LH, Reuter V, Russo P, Marion S, Mazumdar M (2004b) Prognostic factors for survival in previously treated patients with metastatic renal cell carcinoma. J Clin Oncol 22(3): 454-463.

Motzer RJ, Hutson TE, Tomczak P, Michaelson MD, Bukowski RM, Rixe O, Oudard S, Negrier S, Szczylik C, Kim ST, Chen I, Bycott PW, Baum CM, Figlin RA (2007) Sunitinib versus interferon Alfa in metastatic renal-cell carcinoma. N Engl J Med 356(2): 115-124.

Motzer RJ, Mazumdar M, Bacik J, Berg W, Amsterdam A, Ferrara J (1999) Survival and prognostic stratification of 670 patients with advanced renal cell carcinoma. J Clin Oncol 17(8): 2530.

Murri AMA, Bartlett JMS, Canney PA, Doughty JC, Wilson C, McMillan DC (2006) Evaluation of an inflammation-based prognostic score (GPS) in patients with metastatic breast cancer. Br J Cancer 94(2): 227-230.

Ohno Y, Nakashima J, Ohori M, Hatano T, Tachibana M (2010) Pretreatment neutrophil-to-lymphocyte ratio as an independent predictor of recurrence in patients with nonmetastatic renal cell carcinoma. J Urol 184(3): 873-878.

Pencina MJ, D’ Agostino RB, Vasan RS (2008) Evaluating the added predictive ability of a new marker: from area under the ROC curve to reclassification and beyond. Stat Med 27(2): 157-172.

Supplementary Information accompanies this paper on British Journal of Cancer website (http://www.nature.com/bjc)
Poludasu S, Cavusoglu E, Khan W, Marmur JD (2009) Neutrophil to lymphocyte ratio as a predictor of long-term mortality in African Americans undergoing percutaneous coronary intervention. Clin Cardiol 32(12): E6-E10.

Proctor MJ, McMillan DC, Morrison DS, Fletcher CD, Horgan PG, Clarke SJ (2012) A derived neutrophil to lymphocyte ratio predicts survival in patients with cancer. Br J Cancer 107(4): 695-699.

Ramsey S, Lamb GWA, Aitchison M, Graham J, McMillan DC (2007) Evaluation of an inflammation-based prognostic score in patients with metastatic renal cancer. Cancer 109(2): 205-212

Ravaud A, Hawkins R, Gardner JP, von der Maase H, Zantl N, Harper P, Rolland F, Audhuy B, Machiels J-P, Pétavy F, Gore M, Schöffski P, El-Hariry I (2008) Lapatinib versus hormone therapy in patients with advanced renal cell carcinoma: a randomized phase III clinical trial. J Clin Oncol 26(14): 2285-2291.

Smith RA, Bosonnet L, Raraty M, Sutton R, Neoptolemos JP, Campbell F, Ghaneh P (2009) Preoperative platelet-lymphocyte ratio is an independent significant prognostic marker in resected pancreatic ductal adenocarcinoma. Am J Surg 197: 466-472.

Suzuki K, Aiura K, Ueda M, Kitajima M (2004) The influence of platelets on the promotion of invasion by tumor cells and inhibition by antiplatelet agents. Pancreas 29(2): 132-140.

Vickers AJ (2011) Prediction models: revolutionary in principle, but do they do more good than harm? J Clin Oncol 29(22): 2951-2952.

Yamanaka T, Matsumoto S, Teramukai S, Ishiwata R, Nagai Y, Fukushima M (2007) The baseline ratio of neutrophils to lymphocytes is associated with patient prognosis in advanced gastric cancer. Oncology 73: 215-220.

Zahorec R (2001) Ratio of neutrophil to lymphocyte counts-rapid and simple parameter of systemic inflammation and stress in critically ill. Bratisl Lek Listy 102(1): 5-14.

This work is published under the standard license to publish agreement. After 12 months the work will become freely available and the license terms will switch to a Creative Commons AttributionNonCommercial-Share Alike 3.0 Unported License. 